\title{
Characterisation of the recreational fishery for southern rock lobster, Jasus edwardsii, in Tasmania, Australia: implications for management
}

JEREMY M. LYLE

ALASTAIR J. MORTON

JANE FORWARD*

Tasmanian Aquaculture and Fisheries Institute

University of Tasmania

Private Bag 49

Hobart

TAS 7001, Australia

email: Jeremy.Lyle@utas.edu.au

*Present address: Department of Education, GPO Box 169, Hobart, TAS 7001, Australia.

\begin{abstract}
Southern rock lobster (Jasus edwardsii) support significant commercial and recreational fisheries in Tasmania, Australia. Since the mid 1990s the number of persons holding recreational lobster licences increased by over $80 \%$, with c. 15500 persons licensed in 2002/03. Assessment of the recreational fishery has been undertaken periodically since 1996 using a telephone-diary survey method. The fishery was concentrated off the south-east and east coasts of Tasmania and characterised by strong seasonality in catch and effort, which peaked markedly early in the fishing year (November-January). Although pots were the most popular fishing method, daily catch rates by divers were more than double those for pots. Divers selectively harvested larger lobsters than those taken by pots and more frequently attained the daily bag limit of 5 lobsters. The estimated recreational harvest increased significantly since 1996/97 and in 2002/03 effectively reached a management trigger level of $10 \%$ of the total allowable commercial catch, flagging a review of recreational management arrangements.
\end{abstract}

M04068; Online publication date 8 June 2005 Received 17 March 2004; accepted 21 July 2004
Keywords southern rock lobster; Jasus edwardsii; recreational lobster fishery; recreational fishing survey; recreational-commercial fishery interactions

\section{INTRODUCTION}

Southern rock lobster (Jasus edwardsii (Hutton)) provide the basis for a major commercial fishery as well as being a highly prized catch for recreational fishers in Tasmania, Australia. The species is harvested commercially by pots whereas recreational fishers are permitted to use a variety of methods, including pots, ring or hoop nets, and dive collection. Recreational licences (first introduced in the late 1970s) are required to harvest rock lobster. The licences are method-based and before the mid 1990s comprised rock lobster pot and general dive licences, the latter permitted dive collection of rock lobster, abalone, and scallops. The licensing system was revised in 1995 and the general dive licence was split into rock lobster, abalone, and scallop dive licences. In 1998, a lobster ring net licence was also introduced, effectively closing a loophole in the legal take of rock lobster. Pot fishers are permitted to use one pot, ring net fishers up to four rings, and divers can use artificial breathing apparatus (scuba and surface air supply or hookah). Licences are issued annually, with the fishing year extending from November to the end of the following August. Recreational fishers may, therefore, hold up to three categories of rock lobster licence in any given fishing year. In addition to licensing and closed seasons, minimum size limits and a ban on the taking of females in berry apply to both recreational and commercial sectors. Recreational fishers are also subject to a daily bag of 5 lobsters and a possession limit of 10 lobsters.

Since the introduction of the present licensing system, the number of persons holding at least one recreational lobster licence has increased steadily from c. 8500 to 15500 in 2002/03, representing an overall increase of more than 80\% since 1995 . Increases occurred in each of the licence categories, 
with c. 12300 pot, 6600 dive, and 3200 ring net licences issued during 2002/03. Set against this trend was the introduction in 1998 of quota management in the commercial fishery, with objectives to reduce catches to sustainable levels and allow for rebuilding of legal-sized biomass (Ford 2001). The total allowable commercial catch (TACC) was initially set at $1502 \mathrm{t}$, representing an effective reduction in catches which had averaged over $1700 \mathrm{t}$ per annum for the preceding decade. The TACC was increased to $1523 \mathrm{t}$ in 2002 .

The size of the recreational harvest has been identified as a management performance indicator for the Tasmanian rock lobster fishery. Specifically, if the recreational harvest exceeded $10 \%$ of the TACC in a year, recreational management arrangements would be reviewed (Anon. 1997). The recreational catch also represents an input into the stock assessment model developed to assess stock status and undertake risk assessments under different management scenarios (Punt \& Kennedy 1997; Gardner et al. 2002).

There have been few previous attempts to assess the size of the recreational lobster harvest in Tasmania. A household survey of home food production for the year ending April 1992, established that c. $57 \mathrm{t}$ of rock lobster was "home produced" in Tasmania (ABS 1994), equivalent to $3 \%$ of the commercial catch at the time. More recently, a telephone survey of licensed fishers produced a harvest estimate of c. 111000 lobsters for the 1995/ 96 fishing year, c. 5\% of the commercial harvest by numbers (Lyle \& Smith 1998).

In this paper we present the results of a series of surveys conducted since 1996 which were designed to provide robust and detailed assessments of the recreational lobster fishery, with the capability to disaggregate catch and effort data regionally, temporally, and by fishing method.

\section{MATERIALS AND METHODS}

\section{Survey design}

Recreational (lobster) fishers were surveyed during the 1996/97, 1997/98, 2000/01, and 2002/03 fishing seasons using a telephone-diary method (Lyle et al. 2002). Potential respondents for each survey were selected at random from the recreational licence database. Although the methodology remained consistent during the four surveys, there were differences in sample selection and survey duration between the first two and the last two seasons. The first two were conducted as part of more general surveys of recreational fishers, only a portion of whom possessed rock lobster licences (Lyle 2000). These surveys were also confined to Tasmanian residents (who comprised $98 \%$ of all rock lobster licence-holders in both seasons) and only encompassed a portion of each season (Table 1). Licence databases were grouped into nine strata according to the previous fishing activity level of the licenceholder (days fished in the previous 12 months was recorded as part of the licence application) and the mix of recreational licences held. For the purposes of the current analyses, the data sets were poststratified to include only those licence-holders in the sample and population who held rock lobster licences. In contrast, the latter two surveys included both resident and non-resident licence-holders and surveyed fishers during the entire season (Table 1). Moreover, in 2000/01 a simple random sample was selected whereas in the latter the population was stratified based on whether or not fishers at least held a lobster dive licence (two strata), with a greater sample take from the "diver" stratum. This strategy was designed to increase the precision of dive estimates, recognising that there were roughly half as many dive licences issued compared with pot licences.

\section{Telephone-diary survey method}

Respondents were contacted initially by telephone in October/November, before the commencement of the fishing year, for a screening interview to assess eligibility to participate in the diary survey. Eligibility was based on the respondent's intention to renew their lobster licence(s) in the coming season, with all eligible respondents invited to participate in the follow-up diary survey. Sampling was conducted without replacement, i.e., licence-holders who did not have a telephone listing or could not be contacted were not replaced.

Diary respondents were issued with "memory jogger" diaries (sensu Lyle et al. 2002) and encouraged to record key information for all lobster fishing activities undertaken. Respondents were contacted regularly by telephone throughout the diary period by survey interviewers who recorded details of any fishing activity since the last contact. The frequency of the contact was tailored to the needs and behaviour (level of fishing activity) of individual respondents such that detailed information was routinely collected shortly after each fishing event, reducing potential recall bias problems for any 


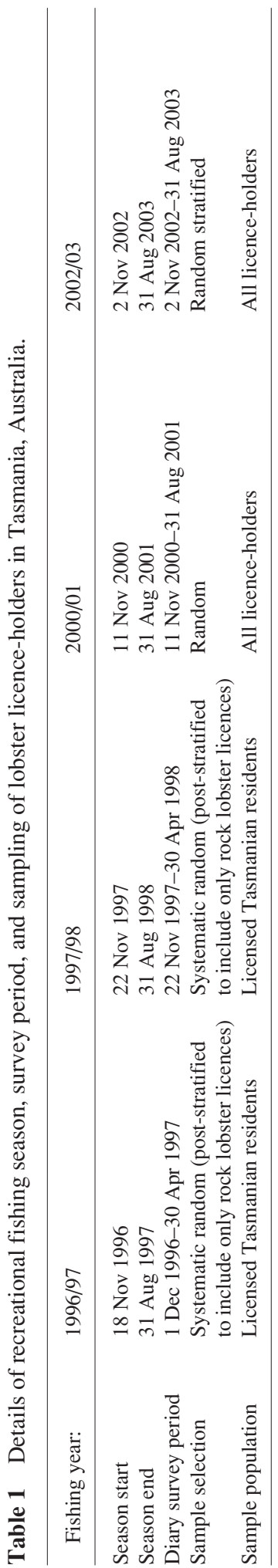

non-diarised data. By maintaining regular telephone contact, interviewers were also able to immediately clarify any misunderstandings or inconsistencies at the time of the interview, thereby ensuring overall data quality and completeness. As a general rule, respondents were contacted at least once a month if no fishing trips were planned or more frequently during periods of activity.

Data collected for each fishing activity or event included date(s), fishing region, method, duration, numbers of lobster kept (harvested) and released or discarded. Pots were generally fished overnight; in a small number of instances pots were not checked for several days, usually because of the inability to retrieve the pots due to unfavourable weather conditions. For the purposes of calculating effort, overnight sets were considered to represent a single pot-day of effort. In addition, regardless of how many times pots or ring nets were checked, or number of dives undertaken on a given day, daily method-based totals (catch and effort) were used in analyses.

\section{Data analyses}

Although initial sample selection was based on the previous year's licence database, licence details for the survey year were used for data expansion. That is, the licensing status (licences held and date of issue) for all diarists was established and expansion factors calculated as the size of the licensed population divided by the number of licensed diarists. Not all diarists renewed licences and in instances where stratification was used in initial sample selection, a very small proportion of diarists, by virtue of licences held in the survey period, changed strata for the purposes of data analysis. As initial sample selection was random these effects were not assumed to have introduced systematic biases.

The progressive increase in the number of licenceholders during the year meant that the sample size (i.e., number of licensed diarists) and total number of licensed fishers changed within the diary enumeration period. For instance, in the years surveyed, $51-60 \%$ of licences were issued by the end of November, $79-83 \%$ by the end of December, and 91-92\% by the end of January. To account for this dynamic, the number of fishers registered on the licence database and the number of diarists licensed at the end of each month provided the basis for calculating expansion factors that were applied to fishing activity that took place in the particular month. Any fishing activity reported by diarists whilst unlicensed (either before renewing a licence 
or by diarists who did not renew licences) was excluded from the analyses. Such unlicensed fishing represented c. $4 \%$ of all reported fishing events.

Since the distributions of effort (days fished) and catch were highly skewed, standard statistical methods that assume normality were not appropriate for calculating confidence intervals. Therefore, the "bootstrap" method was used to estimate confidence limits, determined using the percentile method (Haddon 2001). Where appropriate, stratification was maintained for these analyses and 5000 simulations were conducted.

Calculation of standard errors for population proportions (proportion of licence holders who fished or caught no rock lobster) was based on Pollock et al. (1994).

\section{Size composition}

Size composition information for recreationally caught lobsters was collected during 2002/03 from on-site surveys and information provided by volunteer fishers. Method, fishing location, sex, and carapace length $(\mathrm{mm})$ were recorded. Average weights were determined by converting lengths into weights using the following relationships:

$W=0.000285 L^{3.114}$ males

$W=0.000271 L^{3.135}$ females

where $W$ is body weight ( $\mathrm{g})$, and $L$ is carapace length (mm) (Punt \& Kennedy 1997). A two-way analysis of variance, using Type III sum-of-squares, was used to test carapace length against sex, method, and sex $\times$ method, and contingency table analysis was used to compare sex ratio against method.

\section{Commercial fishery data}

Commercial catch and effort data were obtained from compulsory catch returns in which data were reported on a daily basis by depth and by $1 / 2$ degree fishing blocks. Catches were reported in terms of numbers and weights. To compare commercial and recreational fisheries, commercial catch data were summarised (numbers and weight) for periods corresponding to the surveys and according to the reporting regions used in the surveys. Where commercial fishing blocks were bisected by recreational boundaries, catches within such blocks were apportioned equally between the two appropriate recreational regions. Since the quota year (MarchFebruary) differed to the fishing year (NovemberAugust) these comparisons were subject to variability arising from when commercial fishers chose to take their catch within each quota year.

\section{RESULTS}

\section{Response rates}

When sample loss (no telephone listings) was discounted, screening survey response rates ranged between $90 \%$ and $96 \%$ (mean 93\%), with noncontacts accounting for 3-9\% and refusals less than $1 \%$ of the sample in each of the four surveys. Of those respondents who indicated that they expected to renew their licences and actually did so (eligible respondents), 90-95\% fully responded to the diary surveys (Table 2). Non-response to the diary arose from initial refusal to participate and dropouts during the diary period, the latter occurred almost exclusively because of loss of contact (typically telephone disconnection). No adjustments have been made for non-response because of the very high response rates and only data for fully responding diarists (whether they fished or not) have been used in analyses.

\section{Catch and effort}

During 2000/01, $86.5 \pm 1.9 \%$ ( \pm SE) of licenceholders fished for lobster compared with $88.4 \pm 1.7 \%$ for the 2002/03 fishing year. Inclusive of those who did not fish, $24.6 \pm 2.4 \%$ and $25.0 \pm 2.2 \%$ of licensed fishers harvested no lobster during 2000/01 and 2002/03, respectively.

Estimates of catch (harvest), effort and catch rate by fishing year, and by method are presented in Fig.

Table 2 Number of license-holders surveyed and diary response rates by fishing year.

\begin{tabular}{lcccc}
\hline \multicolumn{1}{c}{ Fishing year: } & $1996 / 97$ & $1997 / 98$ & $2000 / 01$ & $2002 / 03$ \\
\hline Eligible respondents (screening survey) & 362 & 400 & 343 & 442 \\
Accept diary & 351 & 387 & 332 & 409 \\
Full diary response & 333 & 359 & 325 & 400 \\
Response rate $(\%)$ & 92.0 & 89.8 & 94.7 & 90.5 \\
\hline
\end{tabular}


1. Despite the similarity in effort levels for 1996/97 and 1997/98, lower catch rates for the primary fishing methods (pot and dive) in 1997/98 resulted in a $22 \%$ reduction in estimated catch compared with 1996/97. It is noteworthy that although confidence intervals for catch overlapped between years, catch estimates for November 1996 were not available, implying that inter-seasonal differences would have been greater (and possibly significant).

Total catch estimates for 2000/01 and 2002/03 represented substantial increases over the earlier years, largely attributed to increased effort across all methods (Fig. 1). The $27 \%$ increase in harvest between 2000/01 and 2002/03 was due primarily to the combined effects of increased pot effort and higher pot catch rates, with dive catches comparable between years.

Overall, pots were the most frequently used method, deployed on $80-83 \%$ of the total days fished for lobster and accounting for $62-66 \%$ of the total catch in each of the years surveyed apart from 2000/ 01, when they produced $55 \%$ of the total catch (Fig. 1). Although dive effort accounted for just $18-21 \%$ of the total days fished, higher daily catch rates (2.12.6 lobster compared with $0.9-1.2$ lobster for pots) meant that the dive catch was proportionately greater, at between $32 \%$ and $44 \%$ of the total. Although ring net usage was undoubtedly underestimated in the first two surveys, conducted before the introduction of ring net licences, subsequent surveys confirmed that the method was of minor significance (Fig. 1). Annual catch rates for ring nets varied widely between years (1.1-2.5 lobster/day), possibly influenced by small sample sizes.

Catch rates for all methods were highest in 1996/ 97 but were inconsistent in how they varied thereafter, with lowest dive catch rates recorded in $1997 / 98$ and lowest pot and ring net catch rates in 2000/01 (Fig. 1).

\section{Temporal and spatial patterns in catch and effort}

The surveys revealed strong seasonality in the fishery, with three distinct phases of activity; high levels of catch and effort between November and January, intermediate levels between February and April, and low levels for the remainder of the fishing year (Fig. 2). In 2000/01 and 2002/03, the November to January period alone accounted for over $70 \%$ of the total catch and effort whereas the final four months contributed just 5\%. This implies that the 1997/98 survey would have accounted for the vast majority of that year's catch and effort and that inter-annual differences between 1996/97 and 1997/ 98 were underestimated (because of the unavailability of information for November 1996).

Five fishing regions were defined for the 1996/ 97, 1997/98, and 2000/01 surveys and eight regions, corresponding to "areas" used in the rock lobster stock assessment (Punt \& Kennedy 1997), for the 2002/03 survey (Fig. 3). Regionally, the relative distribution of catches has remained consistent over time with catches concentrated off the south-east (SE or Area 1) and east (E or Areas 2-3) coasts (Fig. 3). The combined catch from these regions accounted for $67-75 \%$ of the total (numbers) in each of the years surveyed. North coast (NE and NW or Areas 4-5) catches represented c. $14 \%$ of the total whereas a further $12-18 \%$ of the total was taken from the west coast (W or Areas 6-8).

Spatial structuring of the fishery based on method was also evident. The majority of the combined south-east and east coast harvest was taken by pots (62-79\% depending on fishing year), with dive collection of secondary importance (21-38\%). By contrast, dive collection consistently dominated north coast catches (64-86\%) with pots accounting for the bulk of the remainder (14-35\%). Pots were the main capture method $(48-60 \%)$ off the west coast, followed by dive collection (20-46\%) and, contrary to elsewhere, ring net catches were of some significance (6-24\%).

\section{Daily catch by method}

Catch distributions differed markedly by fishing method (Fig. 4). The combined data set indicated that overall, $47 \%$ of pot-days (range of $45-50 \%$ depending on fishing year) yielded no retained catch and $27 \%$ produced only 1 lobster. The bag limit of 5 rock lobster was rarely attained or exceeded $(<3 \%$ of pot-days). By contrast, success rates for divers were substantially higher, with $24 \%$ of the total dive effort (range of 17-28\%) resulting in no retained catch and, significantly, the bag limit was achieved (or exceeded) on almost $25 \%$ of all diver-days (Fig. 4). Dive method also proved to be an important factor. Divers using hookah achieved the greatest success rates, taking the bag limit in over $35 \%$ of dive-days compared with $17 \%$ for scuba and $11 \%$ for snorkel methods (Fig. 4). Mean annual catch rates ranged between 2.8 and 3.3 lobster/day for hookah compared with 1.6-2.8 for scuba and 1.0-2.2 for snorkel. Catch distributions for ring nets tended to be intermediate between pots and diving, with nil catches reported on $39 \%$ and the bag limit reached on $20 \%$ of the days fished with rings (Fig. 4). 

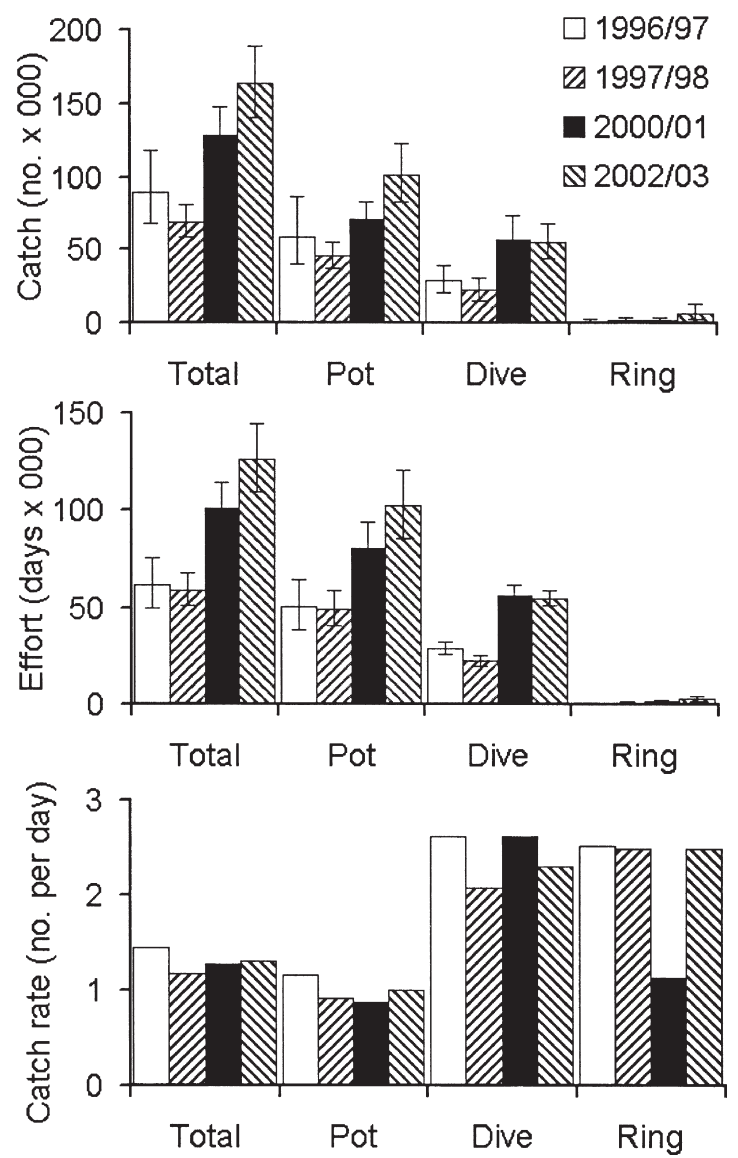

Fig. 1 Estimated recreational catch (number harvested), effort (days fished), and catch rate (number per day) by method and by fishing year for lobster in Tasmania, Australia. Error bars represent $95 \%$ confidence interval.

\section{Size composition}

Lengths of 491 dive and 251 pot-caught lobster taken from the south-east and east coasts of Tasmania were available (Fig. 5). Analysis of variance demonstrated significant method $(F=59.6$; d.f. $=1 ; P<0.001)$, and $\operatorname{sex}(F=22.2$; d.f. $=1 ; P<0.001)$ effects, and a significant sex $\times$ method interaction $(F=9.3$; d.f. $=$ $1 ; P=0.002)$. Dive-caught lobster were significantly larger than pot-caught lobster, averaging $124 \mathrm{~mm}$ and $114 \mathrm{~mm}$ respectively, with males larger than females. The estimated average weight for divecaught lobster was $1006 \mathrm{~g}, 33 \%$ greater than that for pot-caught lobster $(757 \mathrm{~g})$. Contingency table analysis of sex ratio by method produced a highly significant result $\left(\chi^{2}=36.4 ; P<0.001\right)$, with male
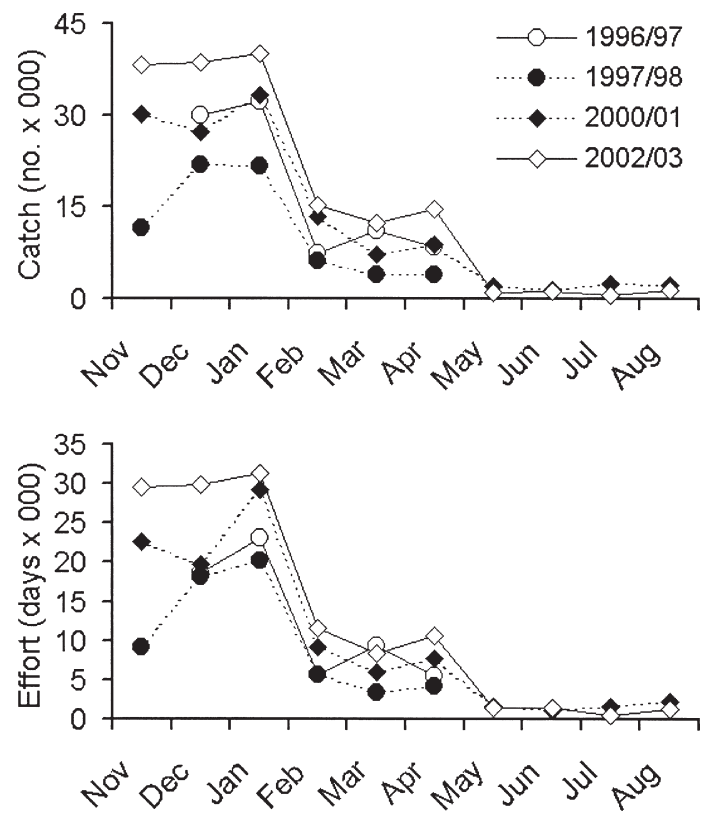

Fig. 2 Estimated recreational catch (number harvested) and effort (days fished) by fishing year and month for lobster in Tasmania, Australia.

to female ratios of $0.66: 1$ and $1.71: 1$ for pot and dive methods respectively.

\section{Comparison with commercial catch}

Relative to the commercial catch (numbers), the recreational harvest increased from c. 5\% in 1996/ 97 to $12.5 \%$ in 2002/03 (Fig. 6). The sharp increase in the recreational proportion between 2000/01 and 2002/03 was partly the result of increased recreational catch but also a reduction in commercial landings during the 2002/03 fishing year (noting that the TACC for the 2002 quota year was in fact caught).

The weight of the 2002/03 recreational harvest was approximated by applying mean lobster weights (by method) determined from size composition data to catches for Areas 1-3 and 8. In the absence of size information for the other areas, mean lobster weights based on commercial catch returns were used, with an adjustment factor of 1.33 for dive-caught lobster. Lobsters caught by ring nets were assumed to have the same mean weight as pot-caught individuals. On this basis the 2002/03 recreational harvest was estimated as $148.5 \mathrm{t}$, equivalent to $13 \%$ of the commercial catch taken during the fishing year (Fig. 5). However, relative to the 2002 quota year catch 
Fig. 3 Maps of Tasmania, Australia showing regions or areas used for data reporting and recreational catch estimates (thousands of lobster) by region or area and fishing year. (SE, south-east; E, east; NE, north-east; NW, northwest; W, west; 1 , Area 1; 2, Area 2; 3, Area 3; 4, Area 4; 5, Area 5; 6 , Area $6 ; 7$, Area $7 ; 8$, Area 8.)

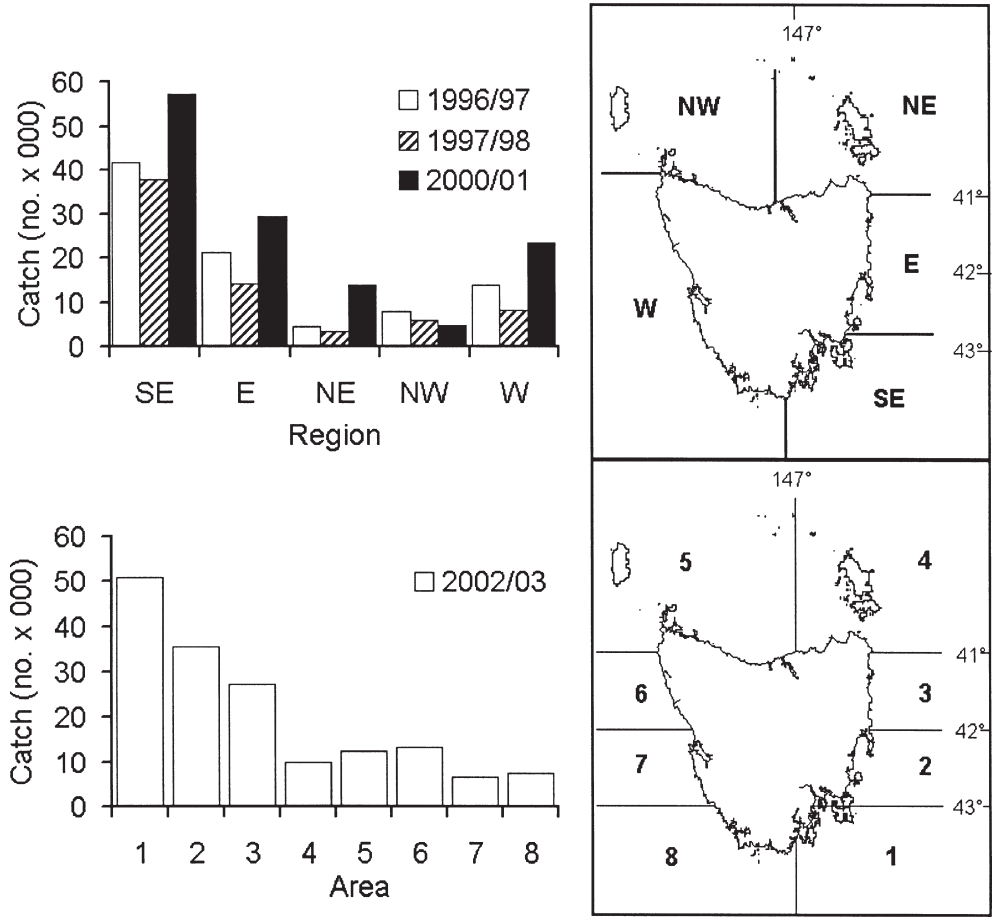

Fig. 4 Relative distribution of recreational catches (numbers harvested per day) by fishing method for lobster in Tasmania, Australia. Data have been combined across years.
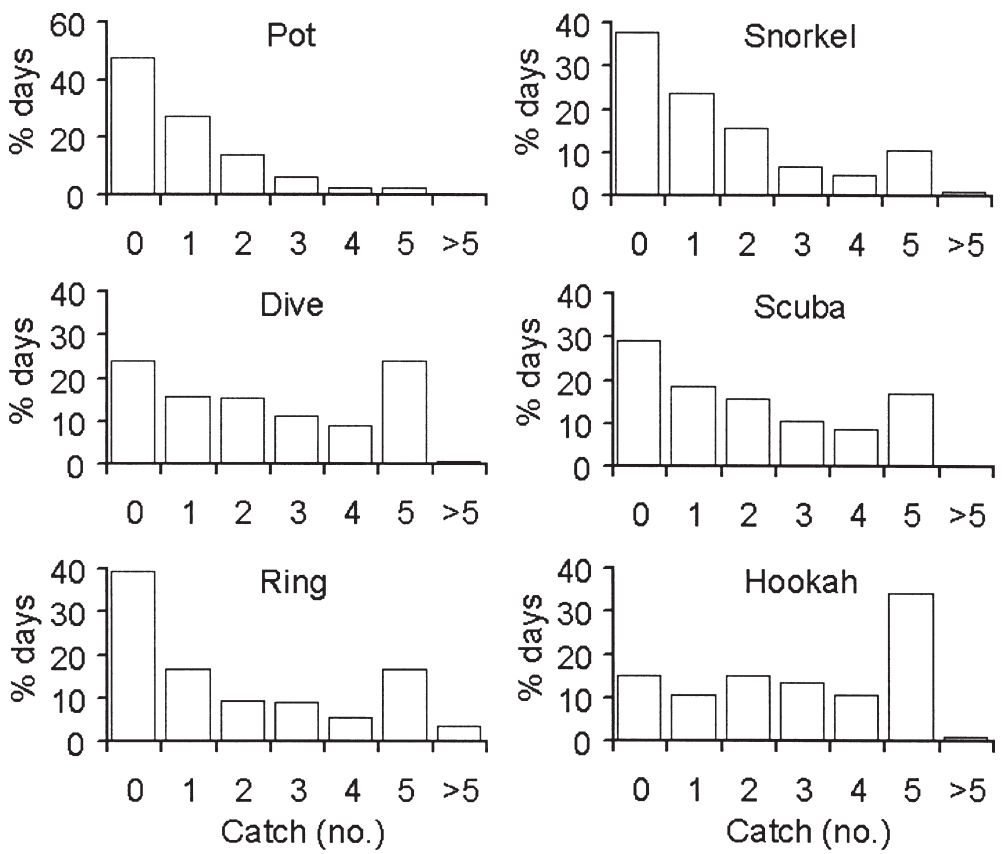


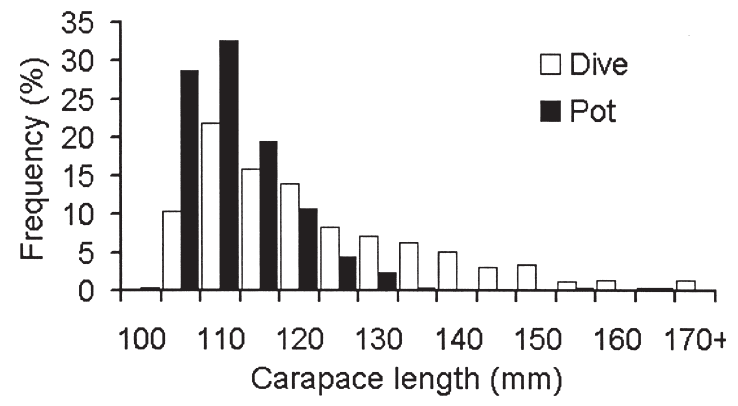

Fig. 5 Relative length-frequency distributions by $5 \mathrm{~mm}$ size class for recreationally caught lobster taken by dive and pot fishing methods in Tasmania, Australia.

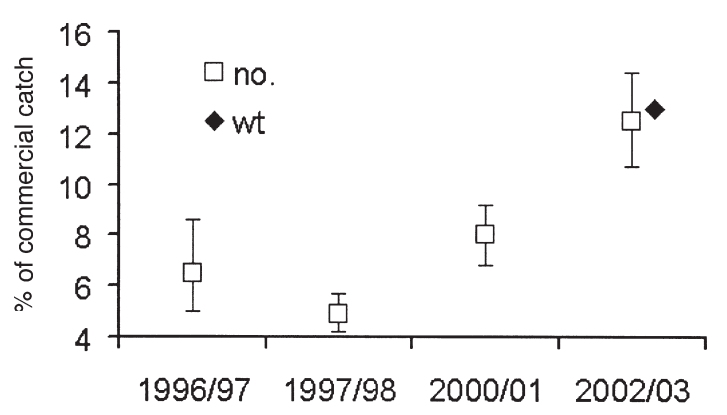

Fishing year

Fig. 6 Tasmanian recreational lobster catch as a percentage of the commercial catch taken during periods corresponding to the recreational surveys, based on numbers (no.) and weight (wt). Error bars represent $95 \%$ confidence interval based on recreational harvest estimates.

(effectively the 2002 TACC) the recreational catch was equivalent to $9.8 \%$ of commercial landings.

In south-east Tasmania (SE or Area 1), the recreational catch relative to the commercial catch (numbers) increased from $25 \%$ to $41 \%$ between 1996/97 and 2002/03 (Fig. 7). East coast (E or Areas 2-3) catches almost doubled in relative importance over this period, to c. $30 \%$ in 2002/03. By contrast, north (NE and NW or Areas 4-5) and west (W or Areas 6-8) coasts catches remained relatively stable, equivalent to less than $7 \%$ of the total commercial catch in each of the years surveyed.

\section{DISCUSSION}

A variety of methods have been applied to assess and monitor recreational lobster fisheries throughout the world, including direct observation of changes in abundance (Davis 1977; Eggleston \& Dahlgren
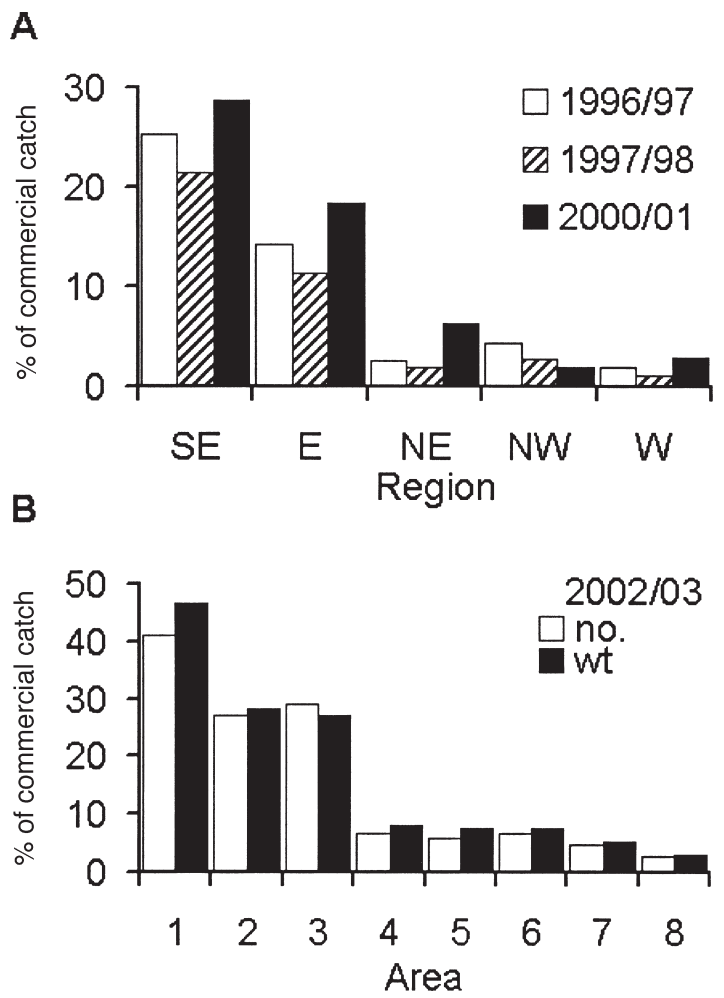

Fig. 7 Tasmanian recreational lobster catch as a percentage of the commercial catch by fishing region or area (refer Fig. 3): A, catches based on numbers for the 1996/97, 1997/98, and 2000/01 fishing years; and B, catches based on numbers (no.) and weight (wt) for 2002/03.

2001), creel surveys (Davis \& Dodrill 1989), mail surveys (Melville-Smith \& Anderton 2000; Muller et al. 2000), telephone surveys (Cockcroft \& Mackenzie 1997; Lyle \& Smith 1998), diary surveys (Bradford \& George 2002), and telephone-diary surveys (McGlennon 1999; Venema et al. 2003). Onsite methods such as direct observation and creel surveys tend to be limited in spatial and temporal scale and thus off-site methods have been more commonly applied in large-scale studies. Off-site methods, however, may suffer from several sources of non-sample error, including non-response and recall biases, that compromise data reliability (Pollock et al. 1994). In respect to these biases, the telephone-diary method as applied here and elsewhere (McGlennon 1999; Lyle 2000; Venema et al. 2003) consistently resulted in very high response rates $(>90 \%)$, and potential problems arising from recall bias were addressed through the combined use of the diary and frequent telephone contact. As such, 
recall periods for non-diarised information were limited to a maximum of about one month. Cockcroft \& Mackenzie (1997) used a multi-stage telephone survey to address recall bias, with a series of samples of licence-holders taken throughout the fishing season and respondents required only to recall their lobster fishing activity for the two weeks before the interview. Typically, however, telephone (or mail) surveys rely on information recalled over much longer periods (Lyle \& Smith 1998; Melville-Smith $\&$ Anderton 2000). Further concerns relating to offsite methods arise from self-reporting of information and include exaggeration of catches (prestige bias) (Pollock et al. 1994). These biases are harder to assess, but by developing rapport between the respondent and interviewer in the telephone-diary method, the respondent was brought into the survey process in terms of understanding objectives and recognising the need for reporting accuracy. We consider, therefore, that the telephone-diary method represented a robust survey approach, providing detailed and reliable information about fishing activities.

Recreational licence numbers in Tasmania have increased steadily since 1995, with high licence usage rates $(>86 \%)$. The main drivers for this trend are unclear. In Western Australia, recreational lobster licence numbers are generally responsive to changes in rock lobster abundance and in fact future catch predictions (based on puerulus settlement indices) are used in the promotion of recreational licence sales (Melville-Smith et al. 2001). Although legal-sized lobster biomass has generally increased in Tasmania since the mid 1990s (Gardner et al. 2002), the overall increase in licence numbers has also been underpinned by substantial turnover in fishers. In most years more than one third of licence holders did not hold a licence in the previous year. A more formal examination of licensing dynamics, including an evaluation of fisher motivations and attitudes in relation to rock lobster, may prove informative in predicting future developments in the Tasmanian fishery.

Increased licence numbers have resulted in the marked expansion of catch and effort, with the recreational harvest almost doubling since 1996/97. Regionally, the fishery was concentrated in the relatively sheltered waters off the south-east and east coasts of Tasmania, adjacent to major population and holiday centres. Limited areas of productive (for rock lobster) inshore coastal reef and generally exposed waters off the north coast, and restricted access points and exposed waters off the west coast have meant that these regions attracted comparatively low levels of recreational fishing pressure for lobster.

Recreational fishing activity was highly seasonal, being most intense immediately following the opening of the season in November and over the summer period, with peaks in effort during January and highest catches recorded in December and January. This pattern reflected the timing of the summer holidays (more days available to fish and favourable weather conditions) and increased lobster availability (reserve accumulation phase of moult cycle). The sharp fall in catch and effort in February was a consistent feature of the fishery, as were slight increases in effort attributable to fishing over the Easter holiday period (March 1997 and April in the other years). Activity levels remained low during the final four months of the fishing year, corresponding to closure of the fishery to the taking of female lobsters at the end of April and the onset of cooler and unsettled weather. High catches early in the season appear typical of other lobster fisheries where there are discrete fishing seasons, for example Western Australia (Melville-Smith \& Anderton 2000), South Australia (McGlennon 1999; Venema et al. 2003), South Africa (Cockcroft \& Mackenzie 1997), and Florida (Muller et al. 2000).

Pots were the main method used by recreational fishers in Tasmania, with 1.8-2.0 times more pot than dive licences issued each year and over four times more days fished using pots than dive collection. Ring nets, although an important method off the west coast, were of minor significance in terms of overall catch and effort. Pots also represent the most commonly used capture method for southern rock lobster in South Australia (Venema et al. 2003) and western rock lobster (Panulirus cygnus) in Western Australia, though there has been a shift towards increased participation by divers in recent years in the Western Australian fishery (Melville-Smith \& Anderton 2000). Melville-Smith $\&$ Anderton (2000) noted that divers consistently reported higher daily catch rates (1.5-2.4 lobster) than potters (1.0-1.5 lobster) in the western rock lobster fishery. Recreational catch rates in the Tasmanian fishery were generally comparable to those for Western Australia and, in terms of pots, were also similar to those for southern rock lobster in the southern zone of the South Australian fishery (0.9 lobster/pot-lift) (Venema et al. 2003).

Consideration of fishing method highlighted factors that have implications for management and impacts on the lobster populations. First, daily catch 
rates for divers were 2.2-3.0 times higher than those for pot fishers, and thus the contribution by dive collection to the catch was proportionally greater than implied by effort levels. Second, artificial breathing apparatus (hookah and scuba) conferred a clear advantage over free-diving for lobster. Highest success (at least one lobster) and catch rates were achieved by divers using hookah, presumably because the gear enabled divers to access confined spaces more readily (lobsters can only be taken using gloved hand in Tasmania) and bottom time was less constrained than for the alternative dive methods. There was some evidence to support the latter; hookah dives were on average longer in duration (between 1.6 and $1.9 \mathrm{~h}$ depending on fishing year) than those reported by scuba divers (1.1-1.6 h). Third, by actively targeting individual lobsters, divers selectively harvested larger lobsters (and proportionally more males) than those taken by passive capture methods (pots). High-grading of catches, presumably in response to bag limits, is a common practice amongst divers and may further contribute to the observed size differences. In addition, there is potential for handling damage (e.g., broken antennae and limbs) as a result of attempted capture or removal from dens before divers can assess size, sex, or condition. The implications of such damage on subsequent growth, reproduction, and survival are generally unknown.

Bag limits represent the primary strategy to constrain recreational catches in Tasmania. In practice, being restricted to a single pot, pot fishers rarely attained the bag limit and thus this management measure had little direct impact on the overall pot catch. By contrast, bag limits had an obvious impact on dive catches, with about one quarter of all dive effort resulting in the capture of at least five lobster. Any measures to reduce bag limits would, therefore, have very different impacts on pot and dive catches.

Relative to the commercial catch, the recreational lobster harvest in Tasmania had more than doubled since the late 1990 s to over $12 \%$, reflecting the combined effects of increased recreational catch and the introduction of catch limits (quota) on the commercial sector. In Western Australia and South Australia, recreational lobster catches have been in the order of 4-5\% of commercial production (Melville-Smith \& Anderton 2000; Venema et al. 2003). In South Africa, recreational catches of Jasus lalandii exceeded 20\% (Cockcroft \& Mackenzie 1997) and in Florida Panulirus argus catches have exceeded 30\% (Muller et al. 2000) of commercial landings in recent years. Statewide comparisons, however, can underestimate regional impacts. This was particularly evident off south-east Tasmania, where in 2002/03 the recreational catch exceeded $40 \%$ of the commercial take. By contrast, recreational catches were comparatively small ( $<7 \%$ of the commercial catch) off the north and west coasts. Furthermore, because of depth limitations on diving and practicalities of hauling pots and ring nets, the recreational fishery operates primarily in shallow waters, at depths of less than c. $20 \mathrm{~m}$. On the other hand, commercial fishers operate over wider areas, including deeper offshore reefs, and catch returns confirmed that typically only about one third of the catch was taken from depths of less than $20 \mathrm{~m}$. Thus where the sectors overlap, the recreational proportion of the catch was higher than implied by comparisons based on total commercial catch. For instance, the 2002/03 recreational harvest equalled $35 \%$ of the commercial catch from shallow-water, whereas off the south-east coast the recreational catch exceeded the commercial catch by $34 \%$ based on numbers and $48 \%$ based on weight.

In reviewing management arrangements for recreational lobster fisheries worldwide, MelvilleSmith et al. (2000) noted that management has tended to focus primarily on issues of sustainability in the commercial fishery. However, with trends towards increased participation and harvest of lobsters in recreational fisheries (e.g., Cockcroft \& Mackenzie 1997; Melville-Smith \& Anderton 2000; Muller et al. 2000; Venema et al. 2003; present study) there is growing recognition of the significance of the recreational sector and the need for it to be accounted for in stock assessments, ecological impacts of fishing, and resource sharing and access. In South Australia resource sharing has been defined in a de facto fashion, with the recreational catch capped at $4.5 \%$ of the total (recreational plus commercial) catch. If this level is exceeded the government will enter the open market to lease quota or pots from the commercial sector to offset the estimated recreational over-catch (Venema et al. 2003). Although such issues have yet to be addressed explicitly in Tasmania, the size of the recreational catch relative to the TACC has been identified as a management performance indicator (Anon. 1997). The recreational catch estimate for 2002/03 effectively reached the management trigger level of $10 \%$ and, as a consequence, a review of recreational management arrangements has been initiated. Notwithstanding such issues, the regional importance of the recreational lobster fishery highlights the need for ongoing assessment to monitor future developments and to 
quantify impacts on stocks. The telephone-diary survey method represents a viable and efficacious approach to provide such information.

\section{ACKNOWLEDGMENTS}

Special thanks to Laurie West, Kewagama Research, who assisted in all aspects of the development and implementation of the survey methodology and to Fiona Ewing who assisted with the management of the first two surveys. Malcolm Haddon provided valuable guidance with data analysis and Caleb Gardner, Dirk Welsford, Philippe Ziegler, and two anonymous referees provided constructive comments on the manuscript. Funding for this work was provided by the Fisheries Research and Development Corporation and the Tasmanian Recreational Fisheries Trust Fund.

\section{REFERENCES}

ABS 1994: Home food production of selected food stuffs, Australia, year ended April 1992. Australian Bureau of Statistics, Catalogue No. 7110.1.

Anonymous 1997: Rock lobster fishery policy document. Unpublished report of the Rock Lobster Working Group, Tasmanian Department of Primary Industry and Fisheries.

Bradford, E.; George, K. 2002: Feasibility of annual surveys for estimating recreational harvest in CRA 1 and CRA 2. New Zealand Fisheries Assessment Report 2002/8. 18 p.

Cockcroft, A. C.; Mackenzie A. J. 1997: The recreational fishery for west coast rock lobster Jasus lalandii in South Africa. South African Journal of Marine Science 18: 75-84.

Davis, G. E. 1977: Effects of recreational harvest on a spiny lobster, Panulirus argus, population. Bulletin of Marine Science 27: 223-236.

Davis, G. E.; Dodrill, J. W. 1989: Recreational fishery and population dynamics of spiny lobsters, Panulirus argus, in Florida Bay, Everglades National Park, 1977-80. Bulletin of Marine Science 44: 78-88.

Eggleston, D. B.; Dahlgren, C. P. 2001: Distribution and abundance of Caribbean spiny lobsters in the Key West National Wildlife Refuge: relationship to habitat features and impact of an intensive recreational fishery. Marine and Freshwater Research 52: $1567-1576$.

Ford, W. 2001: Restructuring the Tasmanian rock-lobster fishery - the effect of two years of management under individual transferable quotas. Marine and Freshwater Research 52: 1641-1648.
Gardner, C.; Frusher, S.; Eaton, L.; Haddon, M.; Mackinnon, C. 2002: Tasmanian rock lobster fishery 2000/01. Unpublished Fishery Assessment Report, Tasmanian Aquaculture and Fisheries Institute. $117 \mathrm{p}$.

Haddon, M. 2001: Modelling and quantitative methods in fisheries. Florida, Chapman \& Hall/CRC. 406 p.

Lyle, J. M. 2000: Assessment of the licensed recreational fishery of Tasmania (Phase 2). Fisheries Research and Development Corporation final report, Project 96/161. 102 p.

Lyle, J. M.; Smith, J. T. 1998: Pilot survey of licensed recreational sea fishing in Tasmania-1995/96. Technical Report Number 51. Department of Primary Industry and Fisheries Tasmania. 55 p.

Lyle, J. M.; Coleman, A. P. M; West, L.; Campbell, D.; Henry, G. W. 2002: New large-scale survey methods for evaluating sport fisheries. In: Pitcher, T. J.; Hollingworth, C. E. ed. Recreational fisheries: ecological, economic and social evaluation. Oxford, Blackwell Science. Pp. 207-226.

McGlennon, D. 1999: Survey of the licensed recreational rock lobster fishery in South Australia 1998/99. Unpublished report, South Australian Research and Development Institute. 20 p.

Melville-Smith, R.; Anderton, S. M. 2000: Western rock lobster mail surveys of licensed recreational fishers 1986/87 to 1998/99. Fisheries Research Report Number 122. Fisheries Western Australia. 39 p.

Melville-Smith, R.; Anderton, S. M.; Caputi, N. 2001: Predicting the recreational western rock lobster (Panulirus cygnus) catch in Western Australia. Marine and Freshwater Research 52: 1527-1534.

Melville-Smith, R.; Phillips, B. F.; Penn, J. 2000: Recreational spiny lobster fisheries-research and management. In: Phillips, B. F.; Kittaka, J. ed. Spiny lobsters: fisheries and culture. Oxford, Fishing News Books. Pp. 447-461.

Muller, R. G.; Sharp, W. C.; Matthews, T. R.; Bertelsen, R.; Hunt, J. H. 2000: The 2000 update of the stock assessment for spiny lobster, Panulirus argus, in the Florida Keys. Fish and Wildlife Conservation Commission, Florida Marine Research Institute Report. 14 p.

Pollock, K. H.; Jones, C. M.; Brown, T. L. 1994: Angler survey methods and their applications in fisheries management. American Fisheries Society Special Publication 25. $371 \mathrm{p}$.

Punt, A. E.; Kennedy, R. B. 1997: Population modelling of Tasmanian rock lobster, Jasus edwardsii, resources. Marine and Freshwater Research 48: 967-980.

Venema, S.; Boxall, V.; Ward, T. M. 2003: Survey of recreational rock lobster fishing in South Australia during 2001/02. Unpublished report, South Australian Research and Development Institute. 42 p. 
